\title{
Detailed Kinetic Modeling of Silicon Nanoparticle Formation Chemistry via Automated Mechanism Generation
}

\author{
Hsi-Wu Wong, ${ }^{\dagger}$ Xuegeng Li,,$\$$ Mark T. Swihart, ${ }^{\ddagger}$ and Linda J. Broadbelt $*, \dagger$ \\ Department of Chemical and Biological Engineering, Northwestern University, 2145 Sheridan Road, \\ Evanston, Illinois 60208, and Department of Chemical and Biological Engineering, University at Buffalo, \\ 506 Furnas Hall, Buffalo, New York 14260
}

Received: January 29, 2004; In Final Form: August 30, 2004

\begin{abstract}
Thermal decomposition of silane can be used to produce silicon nanoparticles, which have attracted great interest in recent years because of their novel optical and electronic properties. However, these silicon nanoparticles are also an important source of particulate contamination leading to yield loss in conventional semiconductor processing. In both cases, a fundamental knowledge of the reaction kinetics of particle formation is needed to understand and control the nucleation of silicon particles. In this work, detailed kinetic modeling of silicon nanoparticle formation chemistry was carried out using automated reaction mechanism generation. Literature values, linear free-energy relationships (LFERs), and a group additivity approach were incorporated to specify the rate parameters and thermochemical properties of the species in the system. New criteria for terminating the mechanisms generated were also developed and compared, and their suitability for handling an unbounded system was evaluated. Four different reaction conditions were analyzed, and the models predicted that the critical particle sizes were $\mathrm{Si}_{5}$ for an initial $\mathrm{H}_{2} / \mathrm{SiH}_{4}$ molar ratio of 90:10 at $1023 \mathrm{~K}$ and $\mathrm{Si}_{4}$ for the same initial composition at $1200 \mathrm{~K}$. For an initial $\mathrm{H}_{2} / \mathrm{SiH}_{4}$ molar ratio of $99: 1$, the critical particle size was larger than or equal to $\mathrm{Si}_{7}$ for both temperatures, but it was not possible to determine the exact critical particle size because of limitations in computational resources. Finally, the reaction pathways leading to the formation of nanoparticles up to the critical size were analyzed, and the important species in the pathways were elucidated.
\end{abstract}

\section{Introduction}

Chemical vapor deposition (CVD) is one of the most commonly used techniques in the semiconductor industry to deposit inorganic thin films or bulk materials. Thermal CVD using silane $\left(\mathrm{SiH}_{4}\right)$ as the precursor has been widely used to fabricate polycrystalline and amorphous silicon. However, the formation of silicon nanoparticles in the gas phase usually limits the growth rate of the film and the equipment utilization, and this contamination is a leading source of yield loss during semiconductor processing. ${ }^{1}$ However, nanostructured silicon with unique optical and electronic properties has attracted great interest in the past few years. Vapor-phase pyrolysis of silane is a convenient and efficient means of intentionally generating silicon nanoparticles, and control of the size and the morphology of the nanoparticles is critical to determining their properties. ${ }^{2}$ Thus, a fundamental understanding of this particle formation chemistry is essential, and knowledge of the reaction kinetics of this system is important in controlling this clustering process.

Reaction kinetics of silicon hydride clustering chemistry have been studied widely both theoretically and experimentally in the literature. Yuuki et al. ${ }^{3}$ proposed a model of silane gasphase clustering chemistry including 11 elementary reactions and 10 chemical species over a temperature range of 550-750 $\mathrm{K}$ based on the experimental results of Purnell and co-workers. ${ }^{4,5}$ They also predicted the formation of nanoparticles starting from $\mathrm{Si}_{5} \mathrm{H}_{12}$. Giunta et al. ${ }^{6}$ developed another model with species containing up to 10 silicon atoms. They concluded that silylenes

* Corresponding author. Tel: 847-491-5351. Fax: 847-491-3728. Email: broadbelt@northwestern.edu.

$\dagger$ Northwestern University.

$\doteqdot$ University at Buffalo. can rapidly insert into other saturated silanes to form larger species. Frenklach et al. ${ }^{7}$ presented a larger model consisting of 117 elementary reactions and 42 species. In their work, the rate parameters for reactions of silanes and silylenes with silicon numbers greater than two were assumed to be the same as those for the similar reactions of disilane $\left(\mathrm{Si}_{2} \mathrm{H}_{6}\right)$. Vepřek et al. ${ }^{8}$ first hypothesized that the formation of rings and complex cyclic structures plays an important role in silicon hydride clustering chemistry. They used experimental measurements of $\mathrm{SiH}_{2}$ concentration and elastic light scattering from particles to support their hypothesis.

Several experimental studies of gas-phase silicon nanoparticle formation during thermal CVD of silane have also been performed. Eversteijn ${ }^{9}$ conducted an experimental study of atmospheric-pressure thermal CVD of silane. An rf-heated horizontal silica reactor was used, and particle formation during silane-hydrogen pyrolysis was observed. The critical silane concentration and the critical temperature at which nanoparticle formation occurred were also defined. Slootman and Parent ${ }^{10}$ additionally performed a study of silicon hydride clustering from silane pyrolysis in a vertical tube reactor over different reaction conditions. The critical conditions such as temperature and silane concentration were proposed to depend on reactor configuration, carrier gas, particle detecting methods, and other parameters. However, these critical conditions are not transferable from one reactor system to another; therefore, determining the dependence of critical conditions on operating parameters is important, and detailed mechanistic modeling can play a key role in constructing different reactor models for different systems.

Swihart and Girshick ${ }^{1}$ recently proposed a detailed mechanism for silicon hydride clustering during silane pyrolysis. In this mechanism, acyclic, cyclic, and polycyclic silanes, silenes, 
TABLE 1: Reaction Families and Rate Parameters Used for Silicon Hydride Clustering Chemistry

\begin{tabular}{|c|c|c|c|c|c|}
\hline & reaction type & typical reaction forms ${ }^{a}$ & $\begin{array}{c}A \\
(1 / \mathrm{s} \text { or } \\
\mathrm{L} / \mathrm{mol} \mathrm{s})\end{array}$ & $\begin{array}{c}E_{\mathrm{o}} \\
(\mathrm{kcal} / \mathrm{mol})\end{array}$ & $\alpha$ \\
\hline 1 & hydrogen elimination & $\begin{array}{l}\left.\mathrm{Si}_{n} \mathrm{H}_{2 n+2}(\text { silane }) \rightarrow \mathrm{Si}_{n} \mathrm{H}_{2 n} \mathrm{~B} \text { ( silylene }\right)+\mathrm{H}_{2} \\
\mathrm{Si}_{n} \mathrm{H}_{2 n} \text { (cyclic silane) } \rightarrow \mathrm{Si}_{n} \mathrm{H}_{2 n-2} \mathrm{~B} \text { (cyclic silylene) }+\mathrm{H}_{2} \\
\mathrm{H}_{2} \mathrm{Si}=\mathrm{SiH}_{2} \rightarrow \mathrm{H}_{2} \mathrm{Si}=\mathrm{Si}:+\mathrm{H}_{2}\end{array}$ & $2 \times 10^{15}$ & 0 & 1 \\
\hline $1-\mathrm{R}^{b}$ & hydrogen addition & $\begin{array}{l}\mathrm{Si}_{n} \mathrm{H}_{2 n} \mathrm{~B} \text { (silylene) }+\mathrm{H}_{2} \rightarrow \mathrm{Si}_{n} \mathrm{H}_{2 n+2}(\text { silane }) \\
\mathrm{Si}_{n} \mathrm{H}_{2 n-2} \mathrm{~B} \text { (cyclic silylene) }+\mathrm{H}_{2} \rightarrow \mathrm{Si}_{n} \mathrm{H}_{2 n} \text { (cyclic silane) }\end{array}$ & & 0 & 0 \\
\hline 2 & silylene elimination & $\begin{array}{l}\mathrm{Si}_{n} \mathrm{H}_{2 n+2}(\text { silane }) \rightarrow \mathrm{Si}_{n-m} \mathrm{H}_{2(n-m)} \mathrm{B} \text { (silylene) }+\mathrm{Si}_{m} \mathrm{H}_{2 m+2} \text { (silane) } \\
\mathrm{Si}_{n} \mathrm{H}_{2 n} \mathrm{~A} \text { (silene) } \rightarrow \mathrm{Si}_{n-m} \mathrm{H}_{2(n-m)} \mathrm{B} \text { (silylene) }+\mathrm{Si}_{m} \mathrm{H}_{2 m} \mathrm{~A} \text { (silene) } \\
\mathrm{Si}_{n+m} \mathrm{H}_{2(n+m)} \mathrm{B} \text { (silylene) } \rightarrow \mathrm{Si}_{n} \mathrm{H}_{2 n} \mathrm{~B} \text { (silylene) }+\mathrm{Si}_{m} \mathrm{H}_{2 m} \mathrm{~B} \text { (silylene) }\end{array}$ & $2 \times 10^{15}$ & 0 & 1 \\
\hline $2-\mathrm{R}^{b}$ & silylene addition & $\begin{array}{l}\mathrm{Si}_{n-m} \mathrm{H}_{2(\mathrm{n}-\mathrm{m})} \mathrm{B} \text { (silylene) }+\mathrm{Si}_{m} \mathrm{H}_{2 m+2} \text { (silane) } \rightarrow \mathrm{Si}_{n} \mathrm{H}_{2 n+2} \text { (silane) } \\
\mathrm{Si}_{n-m} \mathrm{H}_{2(n-m)} \mathrm{B} \text { (silylene) }+\mathrm{Si}_{m} \mathrm{H}_{2 m} \mathrm{~A} \text { (silene) } \rightarrow \mathrm{Si}_{n} \mathrm{H}_{2 n} \mathrm{~A} \text { (silene) } \\
\left.\mathrm{Si}_{n} \mathrm{H}_{2 n} \mathrm{~B}(\text { silylene })+\mathrm{Si}_{m} \mathrm{H}_{2 m} \mathrm{~B} \text { (silylene }\right) \rightarrow \mathrm{Si}_{n+m} \mathrm{H}_{2(n+m)} \mathrm{B} \text { (silylene) }\end{array}$ & & 0 & 0 \\
\hline 3 & silene-silylene isomerization & $\mathrm{Si}_{n} \mathrm{H}_{2 n} \mathrm{~A}$ (silene) $\rightarrow \mathrm{Si}_{n} \mathrm{H}_{2 n} \mathrm{~B}$ (silylene) & $1 \times 10^{13}$ & 7.5 & 1 \\
\hline $3-\mathbf{R}^{b}$ & silylene-silene isomerization & $\mathrm{Si}_{n} \mathrm{H}_{2 n} \mathrm{~B}$ (silylene) $\rightarrow \mathrm{Si}_{n} \mathrm{H}_{2 n} \mathrm{~A}$ (silene) & & 7.5 & 0 \\
\hline & ring opening isomerization & $\mathrm{Si}_{n} \mathrm{H}_{2 n}($ cyclic silane $) \rightarrow \mathrm{Si}_{n} \mathrm{H}_{2 n} \mathrm{~B}$ (silylene) & $2 \times 10^{15}$ & 0 & 1 \\
\hline $4-\mathbf{R}^{b}$ & ring formation isomerization & $\mathrm{Si}_{n} \mathrm{H}_{2 n} \mathrm{~B}$ (silylene) $\rightarrow \mathrm{Si}_{n} \mathrm{H}_{2 n}$ (cyclic silane) & & 0 & 0 \\
\hline
\end{tabular}

${ }^{a}$ Molecules without a suffix are fully saturated silanes. Molecules with an A suffix are silenes. Molecules with a B suffix are silylenes. ${ }^{b}$ The reverse rate constants were computed from the forward rate constants and equilibrium constants.

and silylenes with up to 10 silicon atoms were included, and detailed information such as thermodynamic properties and reactivities of silicon hydride molecules was used. The mechanism contained approximately 2600 reactions and about 220 chemical species. The mechanism was also coupled with a simplified reaction-transport model of nanoparticle formation. ${ }^{11}$ The experimental results were predicted qualitatively. Although this is the most detailed model of silane pyrolysis to date, one simplifying assumption that was invoked was that a single isomer was used to represent each combination of cluster stoichiometry and functionality. The cluster that was selected as representative was the one with the lowest heat of formation. Given that both kinetic and thermodynamic factors may be important, the most important species of a given stoichiometry may not necessarily be the most stable one. Furthermore, the work of Swihart and Girshick used a group additivity scheme that has since been expanded and improved. ${ }^{12}$ Thus, an accurate quantitative prediction of formation rates of nanoparticles has not yet proven successful. A more detailed mechanism has the potential to provide more information about the controlling chemistry and to suggest a strategy of systematic simplification of the reaction mechanisms.

In this work, detailed mechanistic models of silicon hydride clustering chemistry consisting of elementary steps were constructed. Because of the complexity of this reaction system, we used automated mechanism generation software developed by Broadbelt et al. ${ }^{13-18}$ Strategies for generating the mechanisms while maintaining a manageable mechanism size were developed, and an approach for estimating the rate parameters was formulated. The concentration profiles of small- to mediumsized silicon-hydrogen species $\left(<\mathrm{Si}_{9}\right)$ at different reaction conditions were predicted, and the critical cluster sizes for nanoparticle nucleation at various conditions were also estimated. The automated approach facilitates the generation of reaction mechanisms that are tailored to particular reaction conditions, and more representative reaction mechanisms for each condition can be analyzed. The modeling strategies developed in this work were critical for delineating important reaction pathways in silicon nanoparticle formation chemistry, but the methods are sufficiently general that we expect that they would be valuable for developing models of other particle nucleation chemistries, such as the formation of soot particles from polyaromatic hydrocarbon $(\mathrm{PAH})$ compounds during pyrolysis and incomplete combustion of fuels. ${ }^{19-21}$

\section{Model Development}

To build a detailed model of silicon hydride clustering chemistry using automated approaches, the likely types of elementary steps must be identified. For reactions involving one or two silicon atoms, the reactions and rate parameters recommended by Ho et al. ${ }^{22}$ were used, as suggested by previous work. ${ }^{1,11}$ For larger silicon hydrides, the mechanistic steps were grouped into four families of reversible reactions as tabulated in Table 1 (1) hydrogen elimination (and its reverse reaction, silylene insertion 1-R), (2) silylene elimination (and its reverse reaction, silylene addition 2-R), (3) silene to silylene isomerization (and its reverse reaction, silylene to silene isomerization $3-\mathrm{R}$ ), and (4) ring opening (and its reverse reaction, ring formation by intramolecular insertion 4-R). These reaction families were developed on the basis of the studies of Swihart and Girshick ${ }^{1}$ and Giunta et al. ${ }^{6}$ The rate parameters used in these reaction families were estimated using linear free-energy relationships (LFERs). Literature values of preexponential factors were applied, ${ }^{1}$ and the activation energies, $E_{\mathrm{a}}$, were estimated from the heats of reactions, $\Delta H_{\mathrm{rxn}}$, using the EvansPolanyi relationship ${ }^{23,24}$

$$
E_{\mathrm{a}}=E_{\mathrm{o}}+\alpha \Delta H_{\mathrm{rxn}}
$$

where $E_{\mathrm{o}}$ is the intrinsic barrier to reaction and $\alpha$ is the reaction transfer coefficient. These two parameters and the Arrhenius frequency factor, $A$, were assumed to be constants within a particular reaction family; therefore, the rate constant, $k_{\mathrm{ij}}$, of the reaction $\mathrm{j}$ in the reaction family $\mathrm{i}$ was expressed as

$$
k_{\mathrm{ij}}=A_{\mathrm{i}} \exp \left(\frac{-\left(E_{o, i}+\alpha_{\mathrm{i}} \Delta H_{r x n, j}\right)}{R T}\right)
$$

Values of $A_{\mathrm{i}}, E_{\mathrm{o}, \mathrm{i}}$, and $\alpha_{\mathrm{i}}$ were suggested based on information in the literature. Because the insertion of silylene into $\mathrm{H}-\mathrm{H}$ or $\mathrm{Si}-\mathrm{H}$ bonds (reactions $1-\mathrm{R}, 2-\mathrm{R}$, and $4-\mathrm{R}$ ) is barrierless, the activation energies for their corresponding forward reactions (reactions 1,2, and 4) were assumed to be equal to their enthalpy of reaction. This has been confirmed by both experimental and theoretical studies. ${ }^{11}$ Therefore, the parameters for the EvansPolanyi relationship, $E_{\mathrm{o}}$ and $\alpha$, are equal to 0 and 1, respectively, for the forward reactions. As suggested by Swihart and Girshick, ${ }^{1}$ all of the elimination reactions occur via a threecentered transition state and have very similar entropies of 
TABLE 2: Molecules with a Greater Number of Functional Groups Had Higher Standard Heats of Formation Based on G3//B3LYP Calculations

\begin{tabular}{|c|c|c|c|}
\hline Molecular structures & $\begin{array}{l}\text { Number of functional } \\
\text { groups }\end{array}$ & $\begin{array}{c}{ }^{a} \text { Standard heats of } \\
\text { formation } \Delta H_{f, 298}^{o} \\
(\mathrm{kcal} / \mathrm{mol})\end{array}$ & $\begin{array}{c}\text { Standard Entropy at } \\
298 \mathrm{~K} \mathrm{~S}^{2988} \\
(\mathrm{cal} /(\mathrm{mol}-\mathrm{K})) \\
\end{array}$ \\
\hline & 0 & 46.83 & 115.67 \\
\hline & 1 & 101.04 & 113.51 \\
\hline & 1 & 99.04 & 113.53 \\
\hline & 1 & 97.84 & 112.56 \\
\hline & 1 & 89.83 & 110.99 \\
\hline & 2 & 131.01 & 111.38 \\
\hline & 2 & 127.76 & 109.49 \\
\hline & 2 & 125.19 & 114.26 \\
\hline & 2 & 131.19 & 109.10 \\
\hline & 2 & 133.06 & 107.56 \\
\hline & 3 & 156.61 & 103.87 \\
\hline & 3 & 167.49 & 105.97 \\
\hline & 3 & 166.60 & 104.49 \\
\hline
\end{tabular}

${ }^{a}$ Standard heats of formation were from G3//B3LYP calculations with bond additivity corrections (BAC) included.

activation and, thus, the same preexponential factors. The preexponential factors for these reactions were assumed to be $2 \times 10^{15} \mathrm{~s}^{-1}$. This value was chosen based on the known values for silane and disilane decomposition that have been studied experimentally by Ho et al. ${ }^{22}$ The silylene/silene isomerizations, however, are much faster than any other reactions, and little is known experimentally about this reaction family. The rate parameters for this family were thus estimated based on an ab initio electronic structure calculation for $\mathrm{Si}_{2} \mathrm{H}_{4} \mathrm{~B}$ isomerization to $\mathrm{Si}_{2} \mathrm{H}_{4} \mathrm{~A}$ by Swihart and $\mathrm{Carr}^{25}$ (where B denotes a silylene and $\mathrm{A}$ denotes a silene) with a preexponential factor of $10^{13}$ $\mathrm{s}^{-1}$ and an intrinsic barrier of $7.5 \mathrm{kcal} / \mathrm{mol}$. The rate parameters for each reaction family are also summarized and tabulated in Table 1.

The rate constant of the corresponding reverse reaction was expressed as

$$
k_{\mathrm{r}}=\phi \frac{k_{\mathrm{f}}}{K_{\mathrm{c}}}
$$

where $\phi$ is the ratio of the reaction path degeneracy of the forward to the reverse reaction and $K_{\mathrm{c}}$ is the concentration-based equilibrium constant, which can be related to the pressure-based equilibrium constant, $K_{\mathrm{p}}$, and the activity-based equilibrium constant, $K_{\mathrm{a}}$, by ${ }^{26}$

$$
K_{\mathrm{c}}(T)=K_{\mathrm{p}}(T) \times(R T)^{-\Delta v}=\left(\frac{R T}{1 \mathrm{~atm}}\right)^{-\Delta v} \times K_{\mathrm{a}}(T)
$$

where $\Delta v$ is the change of the stoichiometric coefficient of the reaction. The activity-based equilibrium constant, $K_{\mathrm{a}}$, which is a function of temperature, can be expressed as

$$
K_{\mathrm{a}}=\exp \left(\frac{-\Delta G_{\mathrm{rxn}}}{R T}\right)=\exp \left(\frac{\Delta S_{\mathrm{rxn}}}{R}\right) \exp \left(\frac{-\Delta H_{\mathrm{rxn}}}{R T}\right)
$$

The heat of formation, standard entropy, and heat capacities at various temperatures were tabulated for each species as it was generated. If these thermochemical data were available experimentally, then they were looked up during generation from a table that is input by the user or from the NIST database ${ }^{27}$ that can be accessed by the mechanism generation software. Otherwise, they were estimated using group additivity methods, ${ }^{28}$ and the group additivity values for silicon-hydrogen molecules as developed in our previous work ${ }^{12}$ were used.

Several reaction rules were invoked to guide the model building process to generate manageable and reasonable reaction mechanisms. First, molecules with multiple functionalities were not allowed to form. Two different types of functional groups were defined, silene atoms participating in a double bond (denoted as $\mathrm{SiA}$ ) and silylene atoms with two nonbonded electrons (denoted as $\mathrm{SiB}$ ). Because molecules with multiple functionalities are more dehydrogenated, and because dehydrogenation is endothermic, the formation of molecules with multiple functionalities is energetically unfavorable. This can be verified from the G3//B3LYP calculations performed and described in our previous work. ${ }^{12}$ Table 2 shows calculated standard enthalpies of formation and standard entropies (at 298 $\mathrm{K})$ for several linear $\mathrm{Si}_{5} \mathrm{H}_{x}(x=12,10,8$, or 6) species with triple, double, single, or no functionality. Because the other product of dehydrogenation is $\mathrm{H}_{2}$, with an enthalpy of formation of zero, the differences in enthalpy of formation are also the enthalpies of reaction for interconversion of species in Table 2. The entropy of reaction for each dehydrogenation (addition of functional group) is also positive; therefore, at sufficiently high temperature, dehydrogenation and formation of multiple functional groups will become favorable. Two of the sets of conditions examined here have a high enough reaction temperature $(1200 \mathrm{~K})$ that the formation of two functional groups is thermodynamically favored over one functional group for linear molecules. However, it is important to note that a cyclic 
TABLE 3: Mechanisms Generated Using the Rate-Based Termination Criterion Showed Moderate Particle Growth

\begin{tabular}{ccccc}
\hline $\begin{array}{c}\text { weighting } \\
\text { factor } \\
\epsilon\end{array}$ & $\begin{array}{c}\text { total species/maximum } \\
\text { Si atom count }\end{array}$ & total reactions & $\begin{array}{c}\text { core species/maximum } \\
\text { Si atom number }\end{array}$ & total core reactions \\
\hline 1 & $82 / 6$ & 129 & $14 / 3$ & 40 \\
$1 \times 10^{-1}$ & $263 / 8$ & 421 & $23 / 4$ & 94 \\
$1 \times 10^{-2}$ & $551 / 8$ & 798 & $31 / 4$ & 126 \\
$1 \times 10^{-3}$ & $573 / 8$ & 821 & $32 / 4$ & 128 \\
$1 \times 10^{-4}$ & $6937 / 10$ & 8666 & $86 / 5$ & 450 \\
$1 \times 10^{-5}$ & $41924 / 12$ & 47026 & $186 / 6$ & 938
\end{tabular}

compound with one functional group is much more thermodynamically favorable than a linear molecule with two functional groups. Thus, a linear molecule with one functional group will prefer to form a cyclic, monofunctional species. In addition, reactivity information for silicon-hydrogen molecules with multiple functionalities is limited in the literature. As a result, neglecting molecules with multiple functionalities is a reasonable first assumption. The only molecule with double functionality that was allowed to form in the system was $\mathrm{Si}_{2} \mathrm{H}_{2}$, which was suggested to be the key component in the formation of silicon nanoparticles in the thermal CVD of silicon via silane. ${ }^{29,30} \mathrm{It}$ has been reported that $\mathrm{Si}_{2} \mathrm{H}_{2}$ forms through the elimination of molecular hydrogen from disilene, $\mathrm{H}_{2} \mathrm{Si}=\mathrm{SiH}_{2}$, and it can insert into $\mathrm{Si}-\mathrm{H}$ or $\mathrm{H}-\mathrm{H}$ bonds in the same manner as silylenes. ${ }^{31,32}$ Three isomers of $\mathrm{Si}_{2} \mathrm{H}_{2}$ were found, and the most stable structure of $\mathrm{Si}_{2} \mathrm{H}_{2}$ is reported to be $\mathrm{Si}\left(\mathrm{H}_{2}\right) \mathrm{Si}^{30}$ Because this postulated structure does not conform to traditional valence rules for silicon, we implemented $\mathrm{Si}_{2} \mathrm{H}_{2}$ as $\mathrm{H}_{2} \mathrm{Si}=\mathrm{Si}$ : in the automated mechanism generation software for convenience. However, the thermochemical properties of $\mathrm{Si}\left(\mathrm{H}_{2}\right) \mathrm{Si}$ obtained from G3//B3LYP calculations were ascribed to it. The rate parameters for the insertion reactions of $\mathrm{Si}_{2} \mathrm{H}_{2}$ were assumed to follow the correlations used for both insertion reactions families (1-R and 2-R) as shown in Table 1.

For ring formation reactions, only 1,3-through 1,6-insertions were allowed as the energetically most favorable reactions, and 1,7- or higher insertions are less likely because of the relatively longer distances between the reactive sites, that is, silylene atoms and the $\mathrm{Si}-\mathrm{H}$ bonds. It is also possible to form complex, polycyclic species via ring formation reactions that are not physically reasonable even though the valences of all of the constituent silicon atoms are correctly satisfied. As a straightforward way to exclude such structures, we prevented the formation of molecules with two or more quaternary silicon atoms in the same biconnected component. We believe this is a general rule that is appropriately strict based on a small set of selected quantum chemical calculations.

\section{Termination Criteria}

The most challenging task of automated mechanism generation is to apply the methodology to unbounded reaction systems, such as silicon nanoparticle formation chemistry, in which new, unique species are continually formed. This type of reaction mechanism would grow to infinite size without the application of external termination criteria. Several approaches have been developed in the literature to control this explosion using automated mechanism generation. The earliest and most straightforward approaches are the heavy atom count termination criterion, in which a maximum reactant size is specified, and the rank-based termination criterion, in which the maximum number of steps away from the initial reactant(s) is specified. ${ }^{14}$ However, no reaction rate evaluation is carried out when the mechanism is built using either of these two approaches. With these approaches, it is likely that not all of the possible reactions that form larger species are generated, and the critical reactions that lead to the important species are missing at the expense of including unimportant reactions leading to minor species of low rank. Therefore, the species generated using these two approaches do not necessarily represent the key molecules in the mechanism, and chemically significant species with higher ranks or larger sizes are likely omitted.

To overcome the limitations of the rank-based and the heavy atom count criteria, the rate-based termination approach was proposed. ${ }^{18,33}$ In this approach, the importance of each species is evaluated on the basis of its formation rate. A user-specified weighting factor, which sets the boundary between "significant" (or equivalently, "core" or "reactive") and "insignificant" species, is applied, and the mechanism size can be tailored using this weighting factor while chemically meaningful reaction mechanisms can still be generated. To evaluate its suitability for silicon hydride clustering chemistry, we carried out automated mechanism generation using the rate-based termination criterion for silane pyrolysis at atmospheric pressure. In this case, the total pressure of the system was $1 \mathrm{~atm}$, with an initial hydrogen to silane molar ratio of $99: 1$, and the reaction temperature was $1023 \mathrm{~K}$. Table 3 shows the results using the ratebased approach as the weighting factor, $\epsilon$, was decreased. As shown in the table, the weighting factor successfully controlled the mechanism size, with the largest mechanism consisting of 186 core species and 938 reactions in the reactive pool. However, particle growth was only moderate, the biggest core species was $\mathrm{Si}_{6}$, and the mechanism exploded when weighting factors smaller than $1 \times 10^{-5}$ were used. This suggests that the isomerization of silicon hydrides took place at a faster rate than particle growth and that particles could only grow after some significant isomers were formed. The rate-based criterion did not permit reactions that produced larger species, but it did allow the interconversion of many smaller isomers.

Several other termination criteria for automated mechanism generation have been proposed in the literature. Klinke and Broadbelt ${ }^{17}$ put forth a radical lumping strategy and incorporated on-the-fly sensitivity analysis to identify the important and necessary species during automated mechanism generation. It was found that the mechanism size was successfully reduced while the essential chemistry was still captured using pentadecylbenzene (PDB) pyrolysis as an example. However, this approach requires that important species be defined at the outset. This is straightforward if the reactant and primary products formed early in mechanism generation are the important species, as was the case for PDB. In our case, however, it is difficult to apply this methodology because the important species are usually the larger species generated that appear after several generations. Faulon and Sault ${ }^{34}$ proposed a method to perform network generation and mechanism reduction simultaneously using sampling techniques. Four different algorithms were developed, and the concentration of the species instead of reaction rates was used for mechanism reduction. Saunders et al. ${ }^{35}$ proposed a methodology to construct the master chemical mechanism of tropospheric volatile organic compound degrada- 
TABLE 4: Heavy Atom Shell Termination Criterion Generates Full Reaction Mechanisms up to a Certain Size

\begin{tabular}{ccc}
\hline $\begin{array}{c}\text { Si number bound } \\
\text { for the products }\end{array}$ & $\begin{array}{c}\text { number of } \\
\text { species }\end{array}$ & $\begin{array}{c}\text { number of } \\
\text { reactions }\end{array}$ \\
\hline 1 & 3 & 2 \\
2 & 7 & 14 \\
3 & 14 & 40 \\
4 & 35 & 134 \\
5 & 109 & 530 \\
6 & 390 & 2298 \\
7 & 1526 & 10294 \\
8 & 6314 & 46938
\end{tabular}

tion using automatic generation strategies. In their work, newly generated species and reactions were included based on heuristics, which were estimated based on the formation rate of each species. Although both techniques described above performed well for the systems for which they were illustrated, it is difficult to apply these methods to silicon nanoparticle formation chemistry, where larger species are formed at significantly lower rates than those for isomerization reactions. Therefore, a new termination criterion that would enable us to elucidate the critical pathways of particle growth that lead to larger species had to be developed.

To this end, a new termination criterion termed the heavy atom shell approach (HAS) was developed that first allowed the isomerization behavior of silicon hydrides to be studied. This termination criterion is very similar to the heavy atom count criterion mentioned earlier, where a bound is placed on the number of heavy atoms in the products of each reaction instead of the reactants. If a product has more silicon atoms than the user-specified bound, the reaction is excluded. In this way, a full mechanism containing all of the possible species up to a certain silicon atom number, based on the reaction families and rules provided, can then be generated. Table 4 shows the results when the heavy atom shell termination criterion was applied to silicon hydride clustering chemistry. The mechanism size grew exponentially as the bound increased and as the number of possible isomers and reactions increased with increasing molecule size. On the basis of our present computational resources, the largest full mechanism generated using the heavy atom shell approach was the mechanism containing all of the possible species up to $\mathrm{Si}_{8}$, which consisted of more than 6000 species and more than 46000 reactions. Because it is impractical to solve this mechanism, the full $\mathrm{Si}_{7}$ mechanism generated from the heavy atom shell approach was selected, which consisted of 1526 species and 10294 reactions. The mechanism was coupled with batch reactor design equations to obtain the concentration profile of each species as a function of time for a total pressure of $1 \mathrm{~atm}, \mathrm{a} \mathrm{H}_{2}$ to $\mathrm{SiH}_{4}$ molar ratio of 99:1, and a temperature of $1023 \mathrm{~K}$. The results are shown in Figure 1, where the concentrations of species with a given number of silicon atoms were summed. As shown in the Figure, the larger species were present in substantially lower concentrations. Equilibration of the system occurred on the time scale of 1-10 $\mathrm{ms}$, which is in agreement with the modeling results of Swihart and Girshick. ${ }^{1}$

On the basis of the concentration information shown in Figure 1 , it was concluded that the most important reactions for particle growth involved molecules with a given silicon number, $N$, reacting to form molecules with one more silicon atom, $N+1$. Two types of insertion reactions were the main pathways for particle growth: the insertion of $\mathrm{SiH}_{2}$ into species of size $N$, and the insertion of silylenes of size $N$ into silane $\left(\mathrm{SiH}_{4}\right)$. Other bimolecular insertion reactions between two large species had significantly lower rates because larger species appeared in

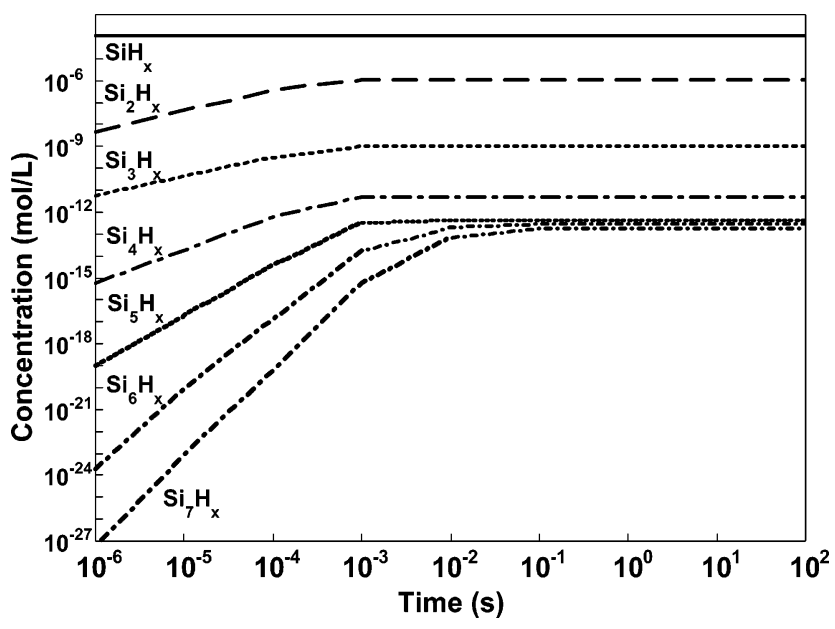

Figure 1. Concentration profiles of species with a particular number of silicon atoms as a function of reaction time from the full $\mathrm{Si}_{7}$ mechanism using the heavy atom shell termination criterion $\left(P_{\text {total }}=1\right.$ atm, $\left.\mathrm{H}_{2,0} / \mathrm{SiH}_{4,0}=99: 1, T=1023 \mathrm{~K}\right)$. The concentration profiles shown are the connection of simulation points at the times of $10^{-6}, 10^{-5}, 10^{-4}$, $10^{-3}, 10^{-2}, 10^{-1}, 1,10$, and $10^{2} \mathrm{~s}$.

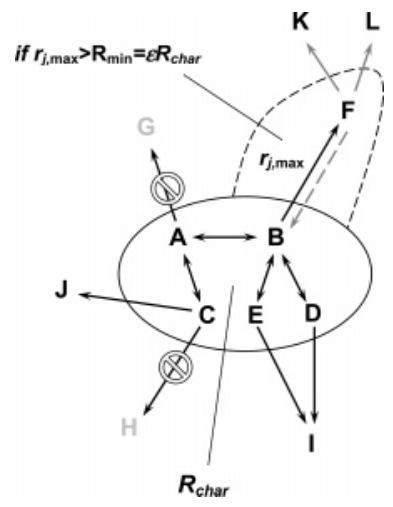

Figure 2. The rate-based termination criterion coupled with the heavy atom shell technique discards species larger than the bound (species $\boldsymbol{G}$ and $\boldsymbol{H}$ in this figure) and, therefore, their rates are not evaluated.

relatively lower concentrations and the rate constants for insertion reactions are roughly independent of size.

Using these insights from the HAS approach, a new hybrid termination criterion was implemented. The rate-based termination criterion was coupled with the heavy atom shell approach. A schematic representation of this approach is shown in Figure 2. Similar to the rate-based approach, the maximum rate of formation or disappearance among all of the core species in the pool (the characteristic rate, $R_{\text {char }}$ ), the minimum allowable formation rate $\left(R_{\min }\right.$, which is equal to the user-specified weighting factor, $\epsilon$, multiplied by $R_{\text {char }}$ ), and the largest formation rate $\left(r_{\mathrm{j}, \max }\right)$ of unreacted species outside the pool are calculated. The values of $R_{\min }$ and $r_{\mathrm{j}, \max }$ are then compared to determine which species is to be added to the pool. However, only the formation rates of the species with the size smaller than or equal to the user-specified heavy atom bound are inspected. Information about unreacted species with sizes larger than the bound, such as species $\boldsymbol{G}$ and $\boldsymbol{H}$ in Figure 2, is not stored, and the corresponding formation reactions are not generated. Furthermore, these molecules are deleted from memory. Using this approach, the demand for computational resources is reduced. As a result, smaller weighting factors can be used, and a larger reaction mechanism consisting of more reactive species can be generated.

Table 5 shows the results of the rate-based generation coupled with the heavy atom shell approach for the same reaction 
TABLE 5: Larger Mechanisms Were Obtained Using Rate-Based Generation Coupled with the Heavy Atom Shell Approach

\begin{tabular}{|c|c|c|c|c|c|c|}
\hline $\begin{array}{c}\text { weighting } \\
\text { factor }^{a} \\
\epsilon\end{array}$ & $\begin{array}{l}\text { heavy atom } \\
\text { bound }\end{array}$ & total species & total reactions & $\begin{array}{l}\text { core species/maximum } \\
\mathrm{Si} \text { atom number }\end{array}$ & total core reactions & $\begin{array}{c}\Delta \\
(\%)\end{array}$ \\
\hline $\begin{array}{l}1 \times 10^{-4} \\
1 \times 10^{-5} \\
1 \times 10^{-6}\end{array}$ & 5 & $\begin{array}{l}103 \\
105 \\
106\end{array}$ & $\begin{array}{l}479 \\
500 \\
516\end{array}$ & $\begin{array}{l}86 / 5 \\
94 / 5 \\
100 / 5\end{array}$ & $\begin{array}{l}450 \\
480 \\
510\end{array}$ & $\begin{array}{r}34.31 \\
0.03 \\
0.00\end{array}$ \\
\hline $\begin{array}{l}1 \times 10^{-4} \\
1 \times 10^{-5} \\
1 \times 10^{-6} \\
1 \times 10^{-7}\end{array}$ & 6 & $\begin{array}{l}258 \\
352 \\
366 \\
371\end{array}$ & $\begin{array}{l}814 \\
1402 \\
1809 \\
2030\end{array}$ & $\begin{array}{l}86 / 5 \\
186 / 6 \\
249 / 6 \\
294 / 6\end{array}$ & $\begin{array}{l}450 \\
938 \\
1490 \\
1858\end{array}$ & $\begin{array}{l}4.23 \\
2.06 \\
0.01\end{array}$ \\
\hline $\begin{array}{l}1 \times 10^{-5} \\
1 \times 10^{-6} \\
1 \times 10^{-7} \\
8 \times 10^{-8}\end{array}$ & 7 & $\begin{array}{l}925 \\
1196 \\
1336 \\
1340\end{array}$ & $\begin{array}{l}2379 \\
3529 \\
6182 \\
6232\end{array}$ & $\begin{array}{l}186 / 6 \\
329 / 7 \\
678 / 7 \\
687 / 7\end{array}$ & $\begin{array}{l}938 \\
1752 \\
4206 \\
4266\end{array}$ & $\begin{array}{r}111.43 \\
0.63 \\
0.63\end{array}$ \\
\hline $\begin{array}{l}1 \times 10^{-5} \\
1 \times 10^{-6} \\
1 \times 10^{-7}\end{array}$ & 8 & $\begin{array}{l}2214 \\
2945 \\
4734\end{array}$ & $\begin{array}{l}4186 \\
6116 \\
15871\end{array}$ & $\begin{array}{l}186 / 6 \\
329 / 7 \\
1311 / 8\end{array}$ & $\begin{array}{l}938 \\
1752 \\
7642\end{array}$ & \\
\hline
\end{tabular}

${ }^{a}$ The critical weighting factor, which is defined as the $\epsilon$ value where $\Delta$ is less than $5 \%$ for each particle size up to $\mathrm{Si}_{7}$, is shown in italics.

TABLE 6: Results Obtained Using Particle Rate-Based Generation Coupled with Heavy Atom Shell Approach

\begin{tabular}{cccccc}
\hline $\begin{array}{c}\text { weighting } \\
\text { factor } \\
\epsilon\end{array}$ & $\begin{array}{c}\text { heavy atom } \\
\text { bound }\end{array}$ & total species & total reactions & $\begin{array}{c}\text { core species/maximum } \\
\text { Si atom number }\end{array}$ & $\begin{array}{c}\text { total core reactions } \\
\Delta(\%)\end{array}$ \\
\hline $1 \times 10^{-6}$ & 5 & 105 & 500 & $94 / 5$ & 480 \\
$1 \times 10^{-6}$ & 6 & 352 & 1402 & $186 / 6$ & 938 \\
$1 \times 10^{-7}$ & & 352 & 1402 & $186 / 6$ & 938 \\
$1 \times 10^{-6}$ & & 1116 & 2822 & $266 / 7$ & 4.23 \\
$1 \times 10^{-7}$ & 7 & 1273 & 5015 & $566 / 7$ & 3238 \\
$8 \times 10^{-8}$ & & 1273 & 5015 & $566 / 7$ & 3238 \\
$1 \times 10^{-6}$ & & 2700 & 4951 & $266 / 7$ & 6.28 \\
$1 \times 10^{-7}$ & 8 & 4468 & 13985 & $1201 / 8$ & 6.28 \\
$8 \times 10^{-8}$ & & 4502 & 14335 & $1238 / 8$ & 6680 \\
\end{tabular}

conditions as used above. Compared to the results generated from the rate-based criterion in Table 3 , it was possible to apply much smaller weighting factors, as low as $8 \times 10^{-8}$. The largest core mechanism generated using this approach consisted of 1311 species and 7642 reactions. The biggest species in this mechanism was $\mathrm{Si}_{8}$. Thus, coupling the heavy atom shell technique with the rate-based criterion (HAS/RB) led to enhanced particle growth compared to the rate-based termination criterion alone.

With the full mechanisms generated using the heavy atom shell approach in hand, it was possible to evaluate the completeness of the mechanisms in Table 5 and thus the efficacy of the rate-based approach in selecting the most kinetically significant species. To quantify the difference between the mechanisms generated using the HAS/RB approach and the corresponding full mechanisms for a given heavy atom bound, a percentage deviation factor, $\Delta$, was defined as

$$
\Delta=\max \left(\left|\frac{\sum C_{\mathrm{i}}-\sum C_{\mathrm{i}}^{\prime}}{\sum C_{\mathrm{i}}^{\prime}}\right|\right) \times 100 \%
$$

where $\Sigma C_{\mathrm{i}}$ is the sum of the concentrations of molecules with size i obtained from the HAS/RB mechanism and $\Sigma C_{\mathrm{i}}{ }^{\prime}$ is the sum of the concentrations of molecules with size $i$ obtained from the corresponding full mechanism. The equilibrium concentration at the final integration time was used in the calculation, and the value for the molecule size with the maximum deviation was assigned to $\Delta$. The values of $\Delta$ are also tabulated in Table 5. From this definition, it is clear that the full mechanism is the limit of the mechanism generated using the HAS/RB approach when the weighting factor, $\epsilon$, is zero. There is also a critical weighting factor for each molecule size, which is the highest weighting factor that can be used to obtain excellent agreement with the full mechanism. As shown in Table 5, the critical weighting factors were $1 \times 10^{-5}$ for $\mathrm{Si}_{5}$ and $\mathrm{Si}_{6}$ and $1 \times 10^{-7}$ for $\mathrm{Si}_{7}$, if excellent agreement was defined as $\Delta$ values less than $5 \%$. It is reasonable that the critical weighting factor for $\mathrm{Si}_{7}$ is smaller than the critical weighting factors for $\mathrm{Si}_{5}$ and $\mathrm{Si}_{6}$ because the concentration of $\mathrm{Si}_{7} \mathrm{H}_{x}$ is smaller than the concentrations of $\mathrm{Si}_{5} \mathrm{H}_{x}$ and $\mathrm{Si}_{6} \mathrm{H}_{x}$, as shown in Figure 1.

The results from the HAS/RB technique suggest that there is a critical weighting factor, $\epsilon_{\text {critical,i, }}$, for each particle size $i$; that is, the deviation between the concentration profiles from the full and the HAS/RB mechanisms did not decrease significantly once an $\epsilon$ value lower than a critical weighting factor was applied. To take advantage of this behavior, we developed a particle size-dependent, rate-based termination criterion. In this approach, the weighting factors are dependent on the molecule size, instead of being universal for all species in the mechanism. A weighting factor is still specified by the user, and its impact on the size of the mechanism is explored. However, the userspecified weighting factor is only applied to the larger molecules for which no critical $\epsilon$ is known and for sizes for which $\epsilon_{\text {critical,i }}$ is less than the $\epsilon$ specified by the user; for example, if a weighting factor of $1 \times 10^{-8}$ is specified by the user for the same reaction conditions discussed earlier, then this weighting factor is only applied to molecules with $\mathrm{Si}_{8}$ or larger using this approach. The critical weighting factor for $\mathrm{Si}_{7}$, that is, $1 \times 10^{-7}$, is used for the molecules with seven silicon atoms, and the critical weighting factor for $\mathrm{Si}_{5}$ and $\mathrm{Si}_{6}\left(1 \times 10^{-5}\right)$ is applied to molecules of $\mathrm{Si}_{6}$ and smaller. Using this strategy, some of the unnecessary $\mathrm{Si}_{5} \mathrm{H}_{x}, \mathrm{Si}_{6} \mathrm{H}_{x}$, and $\mathrm{Si}_{7} \mathrm{H}_{x}$ species that were generated when values of a universal $\epsilon$ below the critical 
weighting factor were used were not be able to form, and computational resources were devoted instead to generate larger mechanisms. Table 6 shows the results from the particle ratebased approach coupled with the heavy atom shell technique (HAS/PRB). In this case, the mechanisms generated were found to be the same size as or smaller than the mechanisms obtained with the same user-specified parameters (i.e., weighting factors and heavy atom bounds) from the HAS/RB approach summarized in Table 5. It is clear that the algorithm filtered out some unnecessary species and that the values of $\Delta$ were still within an acceptable range $(<7 \%)$ for those mechanisms with values of $\Delta$ smaller than $5 \%$ using the HAS/RB approach. It was also possible to generate a larger mechanism by using a weighting factor of $8 \times 10^{-8}$ and an $\mathrm{Si}_{8}$ bound. When this weighting factor was used with the HAS/RB approach, the generation was explosive.

\section{Results and Discussion}

Using the strategies discussed above, automated mechanism generation of silicon nanoparticle formation chemistry was performed at different conditions to predict the critical particle size and the important reaction pathways that lead to this particle formation. Because the dominant reactions for particle growth involve molecules with $N$ silicon atoms converting to molecules with $N+1$ silicon atoms as discussed earlier, the critical particle size, which is the number of silicon atoms in the bottleneck species, can be identified by plotting the total concentration of species of each size as a function of size. The critical particle size would have the lowest total concentration, and a corresponding crossover in the concentration profiles as a function of time would be observed. This definition of critical particle size (or critical nucleus size or critical cluster size) is similar to that used in conventional theories of homogeneous nucleation of a liquid droplet from a supersaturated vapor. In that case, the critical nucleus size is defined as the droplet size for which the change in Gibbs energy for droplet formation from the supersaturated vapor is a maximum. If one could establish equilibrium among all droplet sizes, including those smaller than and larger than the critical size, then the critical size would be the one present at the lowest concentration. Particles larger than the critical cluster size grow irreversibly. Similarly, for silicon hydride cluster nucleation by chemical reaction, we can identify the critical particle size as the cluster size that is present in the smallest concentration at equilibrium among clusters. Here, this concentration is the sum of contributions from many different isomers containing the same number of silicon atoms. On average, the Gibbs energy change for the formation of this ensemble of clusters of the critical size, from silane and hydrogen at a particular set of conditions, is higher than that for the formation of the corresponding ensemble of larger or smaller clusters.

Figure 3 shows the concentration profiles of molecules of different sizes obtained from the largest mechanism in Table 6, which consisted of 1238 species and 6880 reactions. As shown in the Figure, $\mathrm{Si}_{7} \mathrm{H}_{x}$ had the lowest concentration, and the concentration for $\mathrm{Si}_{8} \mathrm{H}_{x}$ crossed the curves for $\mathrm{Si}_{5}-\mathrm{Si}_{7}$ after $10 \mathrm{~ms}$. However, no $\mathrm{Si}_{9}$ species were allowed to form in this mechanism because the bound was placed at $\mathrm{Si}_{8}$, and it is therefore possible that the concentration of $\mathrm{Si}_{8} \mathrm{H}_{x}$ would be lower than $\mathrm{Si}_{7} \mathrm{H}_{x}$ if a mechanism with a bound of $\mathrm{Si}_{9}$ had been successfully generated because of the reactions converting $\mathrm{Si}_{8} \mathrm{H}_{x}$ to $\mathrm{Si}_{9} \mathrm{H}_{x}$. Therefore, the exact critical particle size could not be determined in this case, and it was concluded that the critical particle size under these reaction conditions (99:1 initial $\mathrm{H}_{2} / \mathrm{SiH}_{4}$ molar ratio at $1023 \mathrm{~K}$ and $1 \mathrm{~atm}$ ) is larger than or equal to $\mathrm{Si}_{7}$.

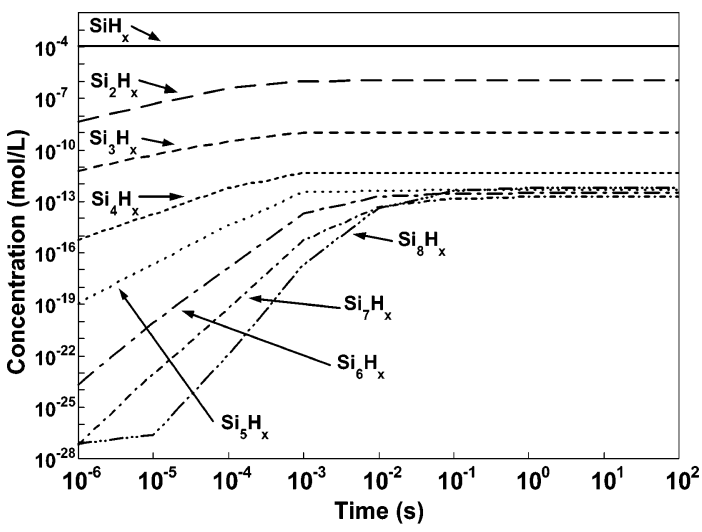

Figure 3. The concentration profiles for an initial $\mathrm{H}_{2} / \mathrm{SiH}_{4}$ molar ratio of $99: 1$ and a temperature of $1023 \mathrm{~K}$ obtained from the mechanism generated using the particle rate-based termination criterion coupled with the heavy atom shell technique. The weighting factor was $8 \times$ $10^{-8}$, and the heavy atom bound was $\mathrm{Si}_{8}$. The critical weighting factors for $\mathrm{Si}_{5}, \mathrm{Si}_{6}$, and $\mathrm{Si}_{7}$ were $1 \times 10^{-5}, 1 \times 10^{-5}$, and $1 \times 10^{-7}$, respectively. The concentration profiles shown are the connection of simulation points at the times of $10^{-6}, 10^{-5}, 10^{-4}, 10^{-3}, 10^{-2}, 10^{-1}, 1,10$, and $10^{2} \mathrm{~s}$.
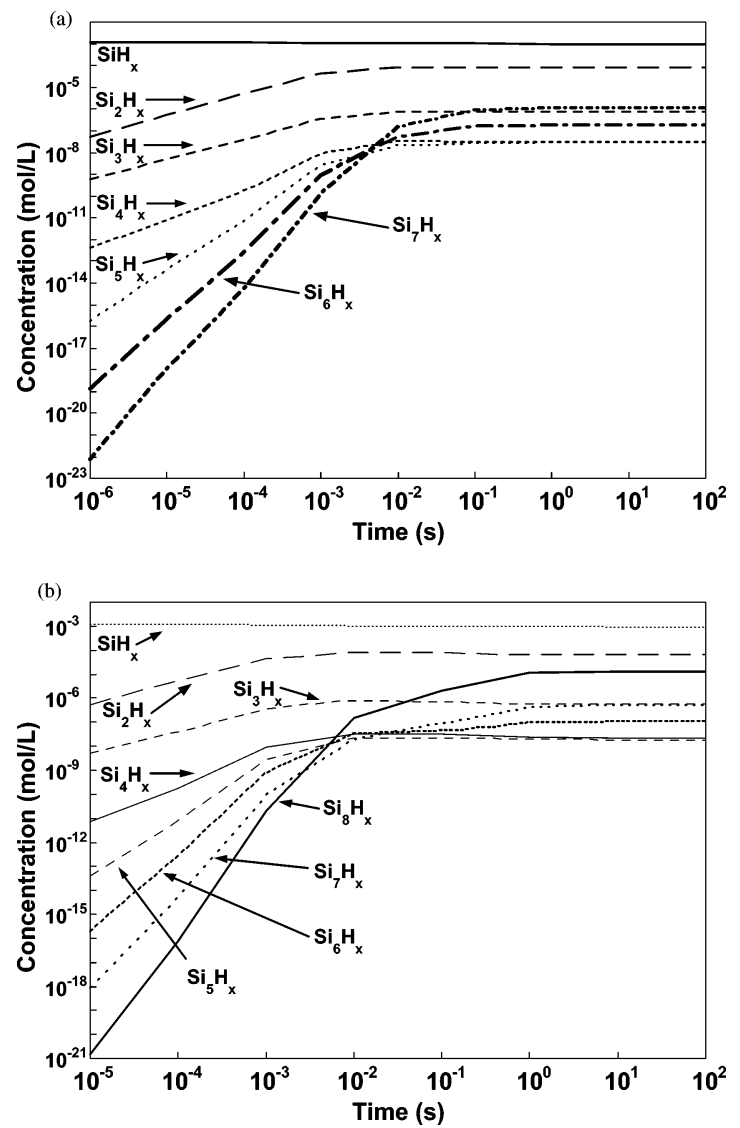

Figure 4. The concentration profiles for an initial $\mathrm{H}_{2} / \mathrm{SiH}_{4}$ molar ratio of 90:10 and a temperature of $1023 \mathrm{~K}$ obtained from (a) a full $\mathrm{Si}_{7}$ mechanism and (b) a mechanism generated from the rate-based termination criterion coupled with the heavy atom shell technique. For b, a weighting factor of 0.01 was used, and the heavy atom bound was $\mathrm{Si}_{8}$. The concentration profiles shown are the connection of simulation points at the times of $10^{-6}, 10^{-5}, 10^{-4}, 10^{-3}, 10^{-2}, 10^{-1}, 1,10$, and $10^{2} \mathrm{~s}$.

The same approach was then used to determine the critical particle size for a different initial $\mathrm{H}_{2} / \mathrm{SiH}_{4}$ molar ratio of 90:10 at the same temperature of $1023 \mathrm{~K}$. The full $\mathrm{Si}_{7}$ mechanism was first solved to obtain the concentration profiles under these conditions, as shown in Figure 4a. In this Figure, $\mathrm{Si}_{5} \mathrm{H}_{x}$ had the lowest concentration, and the crossover was observed as equilibrium was reached, such that $\mathrm{Si}_{7} \mathrm{H}_{x}$ had a higher concentration 
TABLE 7: Same Critical Weighting Factors (0.02) Were Found with Different Heavy Atom Bounds Using Rate-Based Generation Coupled with the Heavy Atom Shell Approach for 90:10 Initial $\mathrm{H}_{2} / \mathrm{SiH}_{4}$ Molar Ratio at $1023 \mathrm{~K}$

\begin{tabular}{|c|c|c|c|c|c|c|}
\hline $\begin{array}{c}\text { weighting } \\
\text { factor }^{a} \\
\epsilon\end{array}$ & $\begin{array}{l}\text { heavy atom } \\
\text { bound }\end{array}$ & total species & total reactions & $\begin{array}{l}\text { core species/maximum } \\
\mathrm{Si} \text { atom number }\end{array}$ & total core reactions & $\Delta(\%)$ \\
\hline 0.05 & & 103 & 481 & $88 / 5$ & 454 & 29.96 \\
\hline 0.02 & 5 & 104 & 487 & $91 / 5$ & 462 & 0.04 \\
\hline 0.01 & & 105 & 499 & $95 / 5$ & 482 & 0.00 \\
\hline 0.1 & & 345 & 1400 & $187 / 6$ & 956 & 27.84 \\
\hline 0.05 & 6 & 348 & 1430 & $196 / 6$ & 990 & 28.74 \\
\hline 0.02 & & 353 & 1729 & $240 / 6$ & 1414 & 3.16 \\
\hline 0.01 & & 361 & 1868 & $264 / 6$ & 1638 & 2.48 \\
\hline 0.05 & & 1221 & 3861 & $425 / 7$ & 2064 & 29.72 \\
\hline 0.02 & 7 & 1268 & 5531 & $615 / 7$ & 3666 & 3.95 \\
\hline 0.01 & & 1301 & 5849 & $663 / 7$ & 4014 & 2.50 \\
\hline 0.05 & & 3976 & 9769 & $838 / 8$ & 3870 & \\
\hline 0.02 & 8 & 4451 & 14381 & $1234 / 8$ & 6926 & \\
\hline 0.01 & & 4630 & 15724 & $1398 / 8$ & 8076 & \\
\hline
\end{tabular}

${ }^{a}$ The critical weighting factor, which is defined as the $\epsilon$ value where $\Delta$ is less than $5 \%$ for each particle size up to $\mathrm{Si}_{7}$, is shown in italics.

than $\mathrm{Si}_{6} \mathrm{H}_{x}$, and $\mathrm{Si}_{6} \mathrm{H}_{x}$ had a higher concentration than $\mathrm{Si}_{5} \mathrm{H}_{x}$. $\mathrm{Si}_{5}$ was therefore identified as the critical particle size.

To evaluate the efficacy of the HAS/RB termination criteria at these reaction conditions, the results using the rate-based termination criterion coupled with the heavy atom shell technique were obtained and are tabulated in Table 7, where the critical weighting factors were found to be uniform for $\mathrm{Si}_{5}, \mathrm{Si}_{6}$, and $\mathrm{Si}_{7}$ at a value of 0.02 among all values examined. This is different from what was observed for the previous reaction conditions, where the critical weighting factors decreased with increasing heavy atom bound. Because the critical particle size was found to be $\mathrm{Si}_{5}$ in this case, the formation rate for species bigger than $\mathrm{Si}_{5}$ is roughly equal to the formation rate of $\mathrm{Si}_{5}$. Therefore, the critical weighting factor of $\mathrm{Si}_{5}$ would be smaller than the critical weighting factors for larger heavy atom bounds. This is consistent with the results in Table 7; when the heavy atom bound was $\mathrm{Si}_{5}$ or larger, the critical weighting factor for $\mathrm{Si}_{5}$ of 0.02 was found for all sizes.

Because the critical weighting factors using the rate-based termination criterion coupled with the heavy atom shell technique were found to be uniform, the particle rated-based approach would not improve the performance of the generation substantially. It was also possible to identify the critical particle size without using the particle rate-based approach for these reaction conditions. The largest mechanism in Table 7 , consisting of 1398 core species and 8076 core reactions, was thus used to solve for the concentration profiles of the species up to $\mathrm{Si}_{8}$ using simple batch reactor design equations. As shown in Figure $4 \mathrm{~b}$, the same crossover behavior of the concentration profiles was observed as seen in Figure 4a for the full mechanism, and the critical particle size was also found to be $\mathrm{Si}_{5}$. The critical particle size at these reaction conditions is smaller than that for a higher $\mathrm{H}_{2} / \mathrm{SiH}_{4}$ ratio, where critical particle size was predicted to be larger than or equal to $\mathrm{Si}_{7}$. This is expected because the reaction system is more dehydrogenated, and the formation of silylenes and their subsequent insertion reactions are favored. The concentrations of individual species were also found to be higher when there was a higher $\mathrm{Si} / \mathrm{H}$ ratio in the initial reaction mixture.

The effects of reaction temperature were also investigated using automated mechanism generation. Reaction mechanisms were constructed using the approaches used previously at 1023 $\mathrm{K}$ for initial $\mathrm{H}_{2} / \mathrm{SiH}_{4}$ molar ratios of both 99:1 (HAS/PRB) and 90:10 (HAS/RB) at a higher temperature of $1200 \mathrm{~K}$. Figure 5a shows the results of solving the full $\mathrm{Si}_{7}$ mechanism for an initial $\mathrm{H}_{2} / \mathrm{SiH}_{4}$ molar ratio of $99: 1$ at $1200 \mathrm{~K}$. Similar to the same
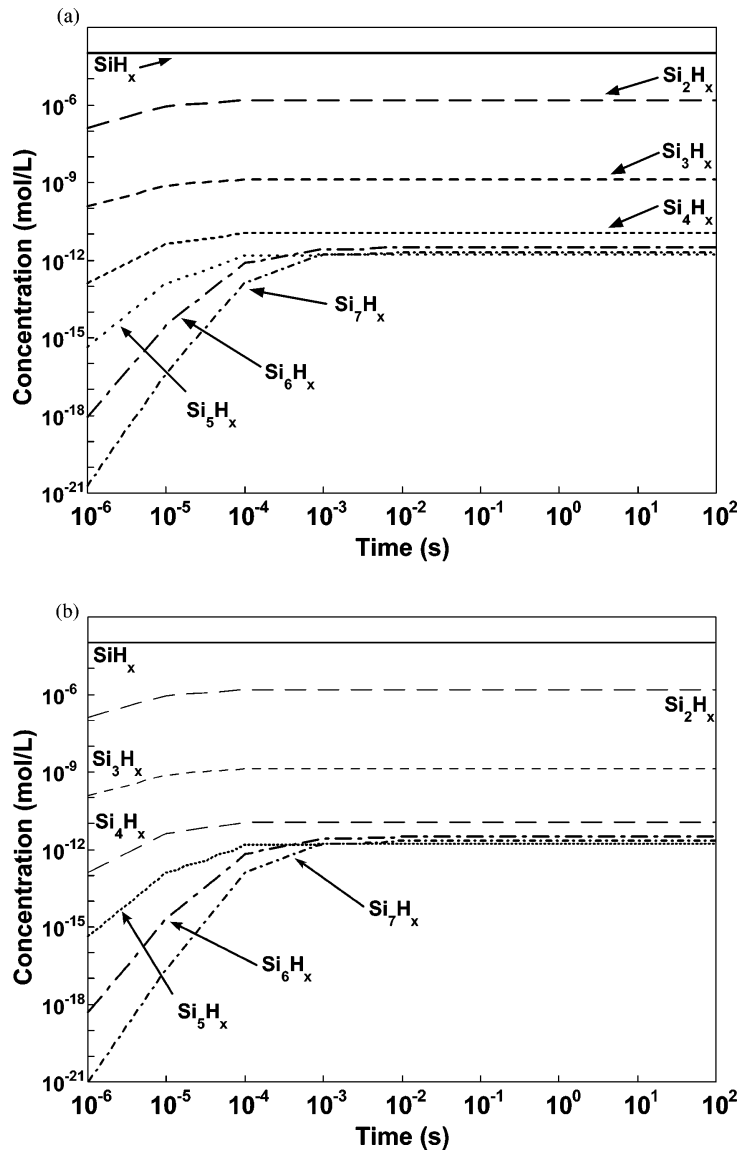

Figure 5. The concentration profiles for an initial $\mathrm{H}_{2} / \mathrm{SiH}_{4}$ molar ratio of $99: 1$ and a temperature of $1200 \mathrm{~K}$ obtained from (a) a full $\mathrm{Si}_{7}$ mechanism and (b) a mechanism generated from the particle rate-based termination criterion coupled with the heavy atom shell technique. For $\mathrm{b}$, a weighting factor of $1 \times 10^{-5}$ was used, and the heavy atom bound was $\mathrm{Si}_{7}$. The critical weighting factors for $\mathrm{Si}_{5}, \mathrm{Si}_{6}$, and $\mathrm{Si}_{7}$ were $1 \times$ $10^{-3}, 1 \times 10^{-3}$, and $1 \times 10^{-5}$, respectively. The concentration profiles shown are the connection of simulation points at the times of $10^{-6}$, $10^{-5}, 10^{-4}, 10^{-3}, 10^{-2}, 10^{-1}, 1,10$, and $10^{2} \mathrm{~s}$.

initial composition at $1023 \mathrm{~K}$, larger species were present in relatively lower concentrations in general. The concentrations of $\mathrm{Si}_{5} \mathrm{H}_{x}, \mathrm{Si}_{6} \mathrm{H}_{x}$, and $\mathrm{Si}_{7} \mathrm{H}_{x}$ were all very close, which indicates that the critical particle size may be somewhere near $\mathrm{Si}_{6}$ or $\mathrm{Si}_{7}$, and it is very likely that it is smaller than the critical particle size at $1023 \mathrm{~K}$. The particle rate-based approach coupled with the heavy atom shell technique was also carried out, and the 

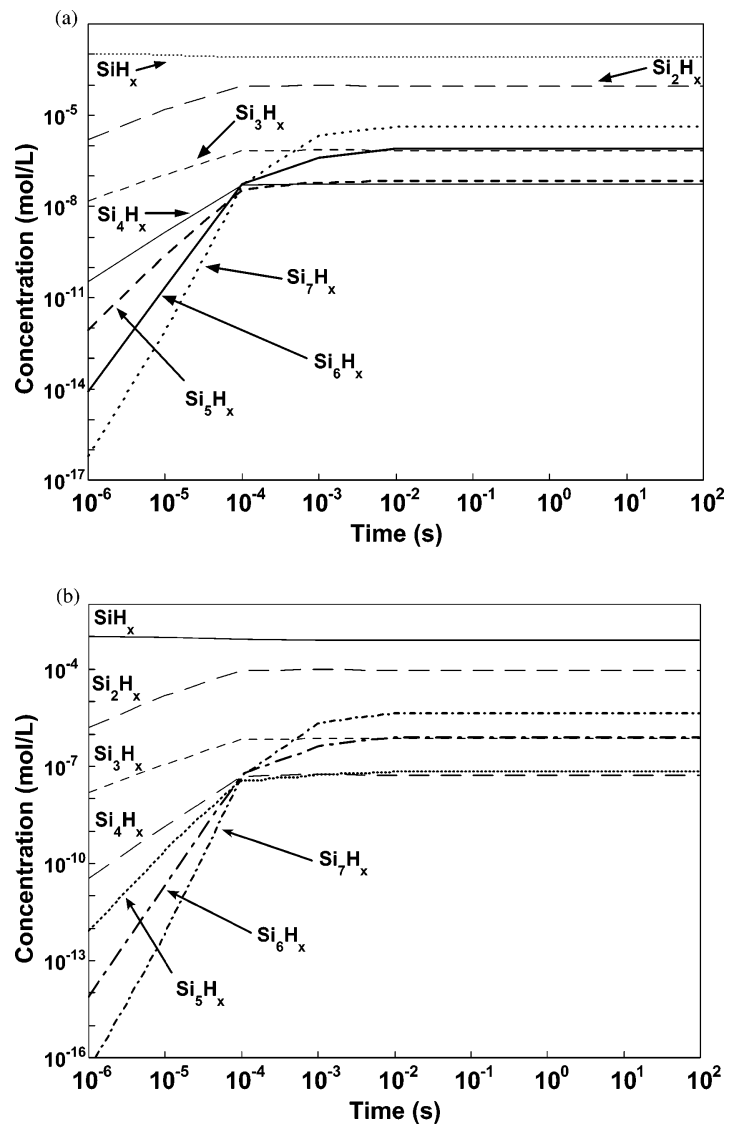

Figure 6. The concentration profiles for an initial $\mathrm{H}_{2} / \mathrm{SiH}_{4}$ molar ratio of 90:10 and a temperature of $1200 \mathrm{~K}$ obtained from (a) a full $\mathrm{Si}_{7}$ mechanism and (b) a mechanism generated from the rate-based termination criterion coupled with the heavy atom shell technique. For b, a weighting factor of 0.5 was used, and the heavy atom bound was $\mathrm{Si}_{7}$. The concentration profiles shown are the connection of simulation points at the times of $10^{-6}, 10^{-5}, 10^{-4}, 10^{-3}, 10^{-2}, 10^{-1}, 1,10$, and $10^{2} \mathrm{~s}$.

concentration profiles obtained from the largest mechanism generated using this approach are shown in Figure 5b. The mechanism consisted of 725 species and 4204 reactions and was generated using an $\epsilon$ of $1 \times 10^{-5}$ and a heavy atom bound of $\mathrm{Si}_{7}$. The critical weighting factors for $\mathrm{Si}_{5}, \mathrm{Si}_{6}$, and $\mathrm{Si}_{7}$ were $1 \times 10^{-3}, 1 \times 10^{-3}$, and $1 \times 10^{-5}$, respectively. Compared to Figure 5a, no significant difference was observed, and the critical particle size was not clearly defined. The results suggest, however, that the critical particle size under these reaction conditions, that is, an initial $\mathrm{H}_{2} / \mathrm{SiH}_{4}$ molar ratio of 99:1 and $1200 \mathrm{~K}$, would be larger than or equal to $\mathrm{Si}_{7}$.

The more dehydrogenated reaction condition, that is, an initial $\mathrm{H}_{2} / \mathrm{SiH}_{4}$ molar ratio of 90:10, was also analyzed at $1200 \mathrm{~K}$, and the concentration profiles using the full $\mathrm{Si}_{7}$ mechanism are shown in Figure 6a. In this graph, $\mathrm{Si}_{4} \mathrm{H}_{x}$ and $\mathrm{Si}_{5} \mathrm{H}_{x}$ had the lowest concentrations, with $\mathrm{Si}_{4} \mathrm{H}_{x}$ being slightly lower than $\mathrm{Si}_{5} \mathrm{H}_{x}$. Equilibrium occurred around $0.1-1 \mathrm{~ms}\left(10^{-4}-10^{-3} \mathrm{~s}\right)$, which was lower than the time for equilibration at $1023 \mathrm{~K}$. Similar to the same initial composition at the lower temperature, $1023 \mathrm{~K}$, the critical weighting factor remained the same when heavy atom bounds greater than four were applied using the HAS/RB technique. This indicated that the particle rate-based termination criterion was also unnecessary at $1200 \mathrm{~K}$. The concentration profiles obtained using the largest mechanism generated from the rate-based termination criterion coupled with the heavy atom shell technique are shown in Figure 6b. The mechanism consisted of 814 species and 4978 reactions and was generated using an $\epsilon$ of 0.5 and a heavy atom bound of $\mathrm{Si}_{7}$. No significant
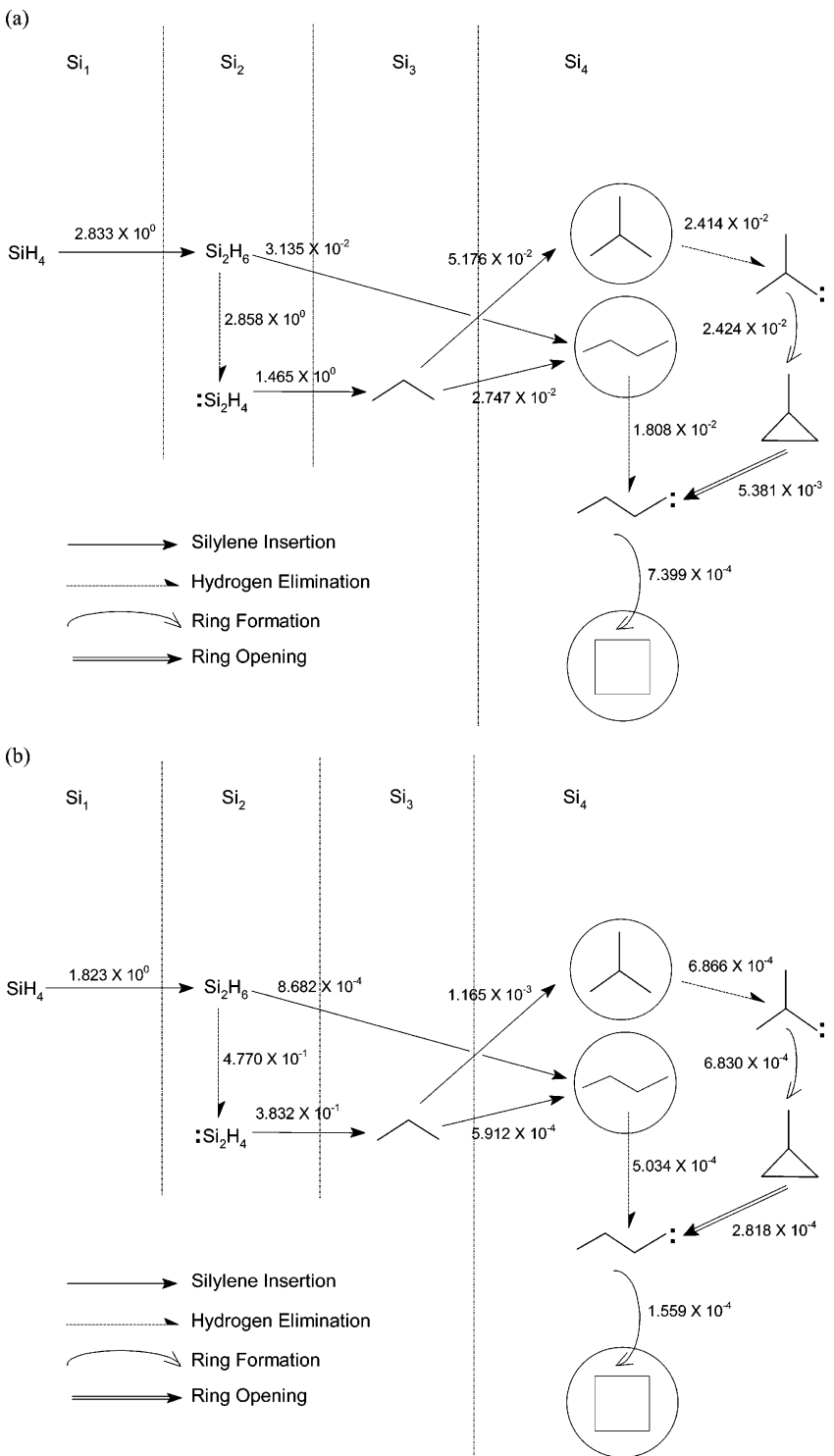

Figure 7. Dominant reaction pathways up to the critical particle size ( $\left.\mathrm{Si}_{4}\right)$ for an initial $\mathrm{H}_{2} / \mathrm{SiH}_{4}$ molar ratio of $90: 10$ at $1200 \mathrm{~K}$ at a reaction time of (a) $100 \mathrm{~s}$ and (b) $0.01 \mathrm{~ms}$. The most abundant $\mathrm{Si}_{4}$ species are shown in circles, and numbers accompanying the arrows indicate net reaction rates in units of $\mathrm{mol} /(\mathrm{L} \mathrm{s})$.

differences were found between the results in Figure $6 a$ and $b$. Both the full mechanism and the HAS/RB mechanism indicate that the critical particle is $\mathrm{Si}_{4}$ at these reaction conditions. The critical particle size thus decreased as temperature increased.

To elucidate further the important reaction pathways that lead to particle growth, we analyzed the reaction mechanisms for an initial $\mathrm{H}_{2} / \mathrm{SiH}_{4}$ molar ratio of $90: 10$ at both temperatures up to the critical particle size. The dominant reaction pathways leading to particle growth at both temperatures are shown in Figure $7(1200 \mathrm{~K})$ and Figure $8(1023 \mathrm{~K})$, respectively. When equilibrium was reached $(100 \mathrm{~s})$ at $1200 \mathrm{~K}$, the most abundant species are cyclotetrasilane $\left(\mathrm{Si}_{4} \mathrm{H}_{8}\right), n$-tetrasilane $\left(n-\mathrm{Si}_{4} \mathrm{H}_{10}\right)$, and silyltrisilane $\left(i-\mathrm{Si}_{4} \mathrm{H}_{10}\right)$, as shown in the circles in Figure $7 \mathrm{a}$. For an earlier reaction time $(0.01 \mathrm{~ms})$ under the same reaction conditions, the reaction pathways leading to $\mathrm{Si}_{4}$ did not change significantly, as shown in Figure $7 \mathrm{~b}$. The dominant reaction pathways at this temperature indicate that the critical species under these reaction conditions are saturated and that trisilane $\left(\mathrm{Si}_{3} \mathrm{H}_{8}\right)$ plays a critical role in the formation of species with the critical particle size $\left(\mathrm{Si}_{4}\right)$. The reaction pathways leading to the critical particle size $\left(\mathrm{Si}_{5}\right)$ at $1023 \mathrm{~K}$ are much more complicated, 
(a)

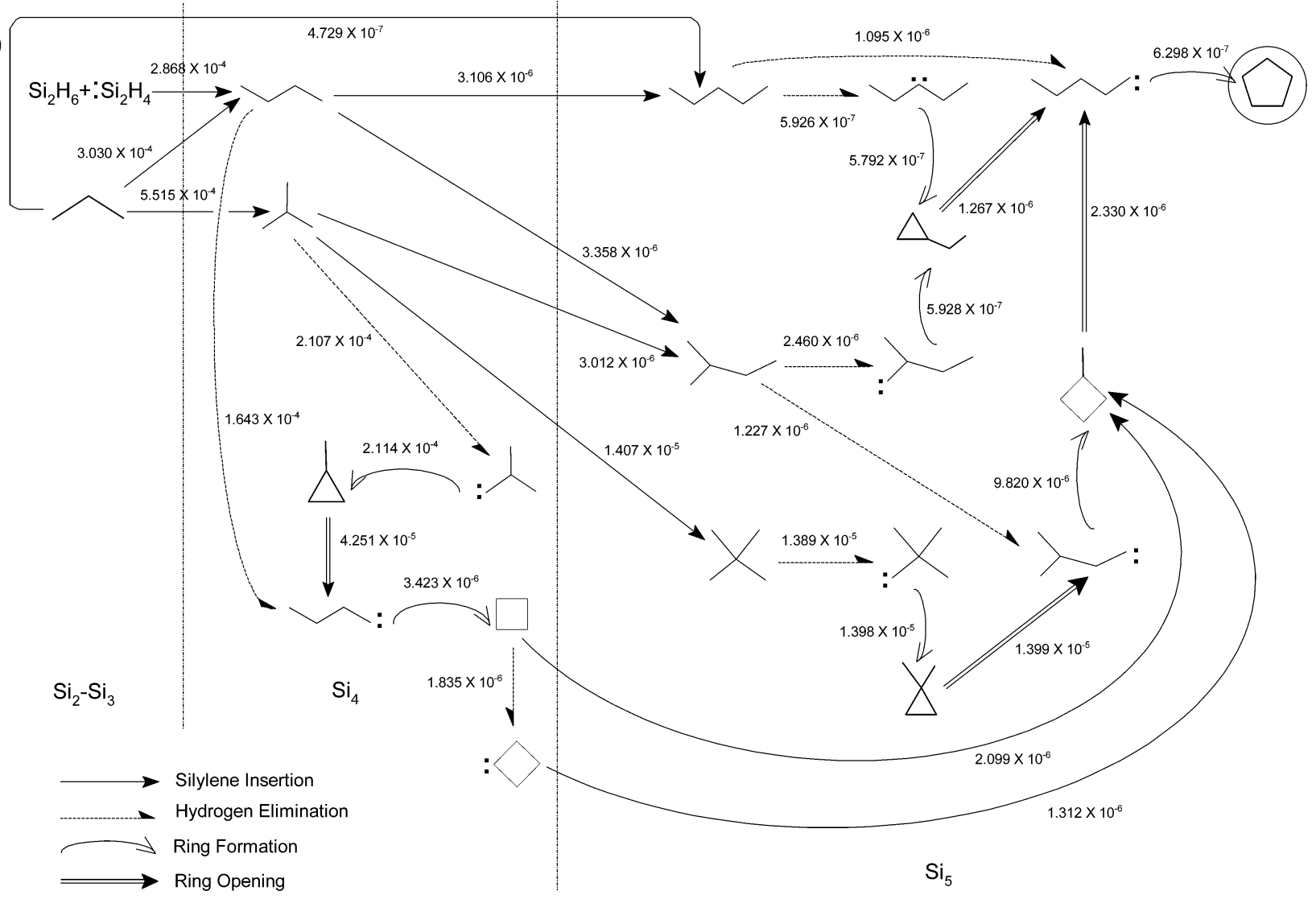

(b)

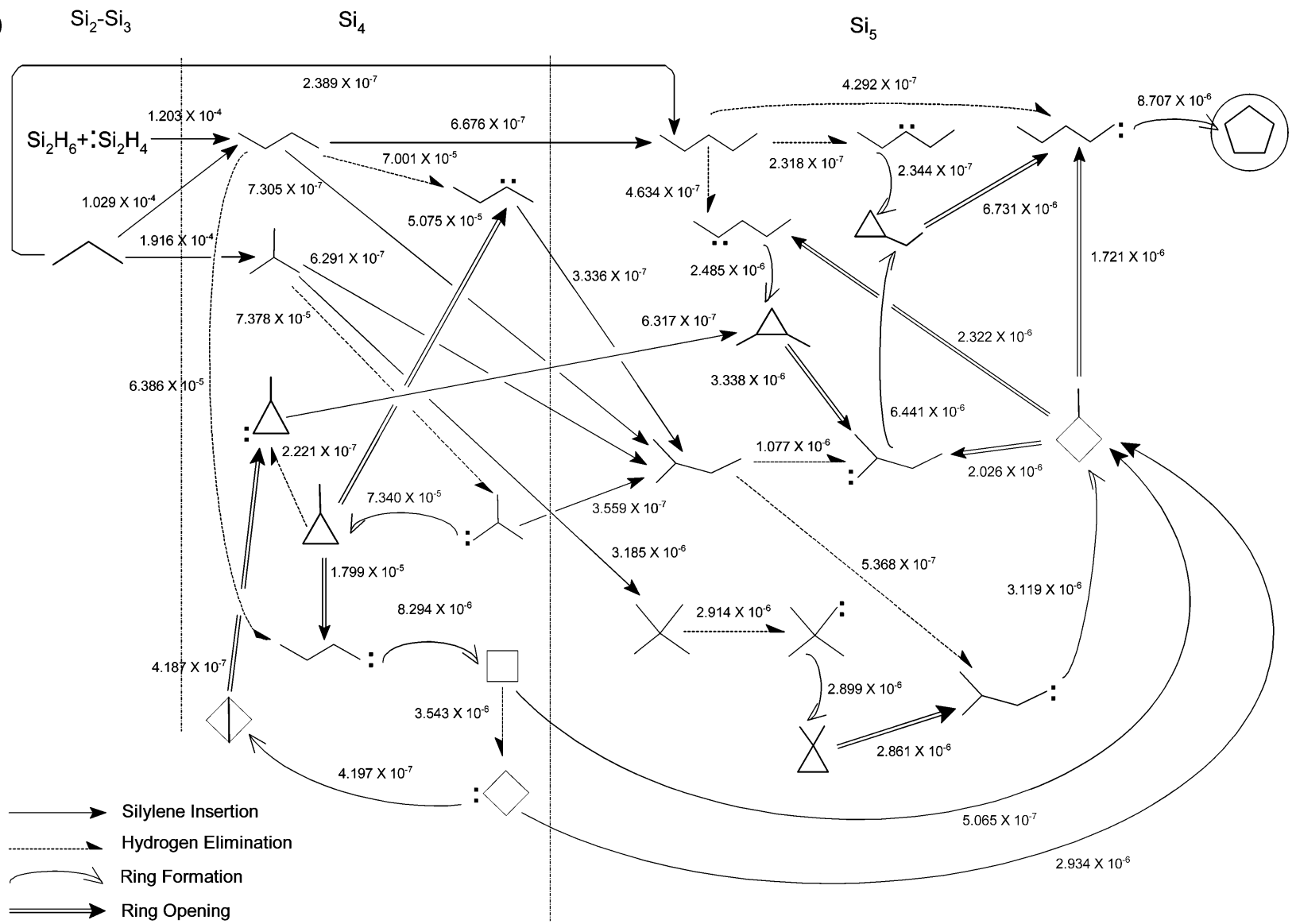

Figure 8. Dominant reaction pathways up to the critical particle size $\left(\mathrm{Si}_{5}\right)$ for an initial $\mathrm{H}_{2} / \mathrm{SiH}_{4}$ molar ratio of $90: 10$ at $1023 \mathrm{~K}$ at a reaction time of (a) $100 \mathrm{~s}$ and (b) $1 \mathrm{~ms}$. The most abundant $\mathrm{Si}_{5}$ species was cyclopentasilane (shown in the circle), and numbers accompanying the arrows indicate net reaction rates in units of $\mathrm{mol} /(\mathrm{L} \mathrm{s})$. The reactions from $\mathrm{Si}_{1}$ to $\mathrm{Si}_{3}$ are similar to those in Figure 7 (not shown). 
as shown in Figure 8. The most abundant $\mathrm{Si}_{5}$ is cyclopentasilane $\left(\mathrm{Si}_{5} \mathrm{H}_{10}\right)$, and saturated $\mathrm{Si}_{4} \mathrm{H}_{x}$, including cyclotetrasilane $\left(\mathrm{Si}_{4} \mathrm{H}_{8}\right)$, $n$-tetrasilane $\left(n-\mathrm{Si}_{4} \mathrm{H}_{10}\right)$, and silyltrisilane $\left(i-\mathrm{Si}_{4} \mathrm{H}_{10}\right)$, are the key reactants to form $\mathrm{Si}_{5}$ before desired, stable structures such as saturated cyclic species, that is, cyclopentasilane, are formed. The reaction mechanism was more complicated for a lower reaction time ( $1 \mathrm{~ms}$, Figure $8 \mathrm{~b})$ than when equilibrium was reached (100 s, Figure 8a). At the earlier reaction time, acyclic $\mathrm{Si}_{4}$ silylenes provide additional important formation pathways for $\mathrm{Si}_{5}$ species, and penta-2-silylene is an additional $\mathrm{Si}_{5}$ species that participates actively in isomerization reactions. Overall, though, the key participants are predominantly the same at both times examined. Note that the key species revealed in this work are not all of the same species as the most stable ones selected as representative for a given stoichiometry and functionality by Swihart and Girshick, ${ }^{1}$ further underscoring the value of the automated mechanism generation technique in creating a more detailed reaction mechanism.

\section{Conclusions}

Automated mechanism generation was performed to elucidate the formation chemistry of silicon nanoparticles. Different termination criteria were developed and compared to evaluate their ability to control this unbounded chemistry. Among the termination criteria examined, the rate-based termination criterion coupled with the heavy atom shell technique showed the most promising particle growth. Application of the particle rate-based approach was also able to enhance the usage of computational resources and to allow larger mechanisms to be generated. The critical particle size was predicted to be larger than or equal to $\mathrm{Si}_{7}$ when the initial molar ratio of $\mathrm{H}_{2} / \mathrm{SiH}_{4}$ was $99: 1$ at 1023 and $1200 \mathrm{~K}$. For more dehydrogenated initial conditions, where an initial molar ratio of $\mathrm{H}_{2} / \mathrm{SiH}_{4}$ of $90: 10$ was used, the critical particle size was predicted to be $\mathrm{Si}_{5}$ at $1023 \mathrm{~K}$ and $\mathrm{Si}_{4}$ at 1200 $\mathrm{K}$. The dominant reaction pathways for particle growth for this initial composition were identified, and saturated molecules were found to play an important role in the clustering process.

Acknowledgment. We are grateful for financial support from the National Science Foundation (NSF-CTS0087315).

\section{References and Notes}

(1) Swihart, M. T.; Girshick, S. L. J. Phys. Chem. B 1999, 103, 64-76.

(2) Li, X.; He, Y.; Talukdar, S. S.; Swihart, M. T. Langmuir 2003, 19, 8490-8496.

(3) Yuuki, A.; Matsui, Y.; Tachibana, K. Jpn. J. Appl. Phys. 1987, 26, $747-754$

(4) Purnell, J. H.; Walsh, R. Proc. R. Soc. London, Ser. A. 1966, 293, $543-561$
(5) Bowrey, M.; Purnell, J. H. Proc. R. Soc. London, Ser. A. 1971, $321,341-359$.

(6) Giunta, C. J.; McCurdy, R. J.; Chapple-Sokol, J. D.; Gordon, R. G. J. Appl. Phys. 1990, 67, 1062-1075.

(7) Frenklach, M.; Ting, L.; Wang, H.; Rabinowitz, M. J. Israel J. Chem. 1996, 36, 293-303.

(8) Vepřek, S.; Schopper, K.; Ambacher, O.; Rieger, W.; VepřekHeijman, M. G. J. J. Electrochem. Soc. 1993, 140, 1935-1942.

(9) Eversteijn, F. C. Philips Res. Rep. 1971, 26, 134-144.

(10) Slootman, F.; Parent, J.-C. J. Aerosol Sci. 1994, 25, 15-21.

(11) Girshick, S. L.; Swihart, M. T.; Suh, S.-M.; Mahajan, M. R.; Nijhawan, S. J. Electrochem. Soc. 2000, 147, 2303-2311.

(12) Wong, H.-W.; Alva Nieto, J. C.; Swihart, M. T.; Broadbelt, L. J. J. Phys. Chem. A 2004, 108, 874-897.

(13) Broadbelt, L. J.; Stark, S. M.; Klein, M. T. Ind. Eng. Chem. Res 1994, 33, 790-799.

(14) Broadbelt, L. J.; Stark, S. M.; Klein, M. T. Chem. Eng. Sci. 1994, 49, 4991-5010.

(15) Broadbelt, L. J.; Stark, S. M.; Klein, M. T. Ind. Eng. Chem. Res. 1995, 34, 2566-2573.

(16) Broadbelt, L. J.; Stark, S. M.; Klein, M. T. Comput. Chem. Eng. 1996, 20, 113-129.

(17) Klinke, II, D. J.; Broadbelt, L. J. AIChE J. 1997, 43, 1828-1837.

(18) Susnow, R. G.; Dean, A. M.; Green, W. H., Jr.; Peczak, P.; Broadbelt, L. J. J. Phys. Chem. A 1997, 101, 3731-3740.

(19) Appel, J.; Bockhorn, H.; Frenklach, M. Combustion and Flame 2000, 121, 122-136.

(20) D’Anna, A.; Violi, A.; D'Alessio, A.; Sarofim, A. F. Combustion and Flame 2001, 127, 1995-2003.

(21) Wang, H.; Frenklach, M. Combust. Flame 1997, 110, 173-221.

(22) Ho, P.; Coltrin, M. E.; Breiland, W. G. J. Phys. Chem. 1994, 98, $10138-10147$.

(23) Evans, M. G.; Polanyi, M. Trans. Faraday Soc. 1936, 32, 13331360 .

(24) Evans, M. G.; Polanyi, M. Trans. Faraday Soc. 1938, 34, 11-29.

(25) Swihart, M. T.; Carr, R. W. J. Phys. Chem. A 1997, 101, $7434-7445$

(26) Sandler, S. I. Chemical and Engineering Thermodynamics; John Wiley \& Sons: New York, 1999.

(27) Stein, S. E.; Lias, S. G.; Liebman, J. F.; Kafafi, S. A. NIST Structure and Properties Users Guide; National Institute of Standards and Technology, 1994.

(28) Benson, S. W. Thermochemical Kinetics; Methods for the Estimation of Thermochemical Data and Rate Parameters; John Wiley \& Sons: New York, 1968.

(29) Ring, M. A.; O’Neal, H. E. J. Phys. Chem. 1992, 96, 10848-10855.

(30) Becerra, R.; Walsh, R. J. Phys. Chem. 1992, 96, 10856-10862.

(31) Breiland, W. G.; Coltrin, M. E.; Ho, P. J. Appl. Phys. 1986, 59 3267-3273

(32) Onischuk, A. A.; Strunin, V. P.; Ushakova, M. A.; Panfilov, V. N. Int. J. Chem. Kinet. 1998, 30, 99-110.

(33) De Witt, M. J.; Dooling, D. J.; Broadbelt, L. J. Ind. Eng. Chem. Res. 2000, 39, 2228-2237

(34) Faulon, J.-L.; Sault, A. G. J. Chem. Inf. Comput. Sci. 2001, 41 894-908.

(35) Saunders: S. M.; Pascoe, S.; Johnson, A. P.; Pilling, M. J.; Jenkin, M. E. Atmos Environ. 2003, 37, 1723-1735. 